\title{
Platinum-Catalyzed Aqueous-Phase Hydrogenation of D-Glucose to D-Sorbitol
}

Xingguang Zhang, Lee J. Durndell, Mark A. Isaacs, Christopher M. A. Parlett, Adam F. Lee,* and Karen Wilson*

European Bioenergy Research Institute, Aston University, Birmingham B4 7ET, United Kingdom

\section{Supporting Information}

ABSTRACT: Aqueous-phase hydrogenation of D-glucose to Dsorbitol was systematically investigated over silica-supported $\mathrm{Pt}$ nanoparticles to elucidate structure-reactivity relations and mechanistic insight. D-Glucose hydrogenation over large $\mathrm{Pt}$ particles competes with its isomerization to D-fructose over low-coordination (electron-deficient) Pt sites; D-sorbitol production by the former process was structure insensitive for nanoparticles spanning 3-17 nm, whereas isomerization was favored by smaller particles, with both pathways independent of the choice of fumed silica or mesoporous SBA-15 support. While D-fructose was readily hydrogenated to Dmannitol under the same reaction conditions, the latter underwent minimal isomerization to D-sorbitol, which is, therefore, a direct product of D-glucose ring opening and subsequent hydrogenation of the aldose conformer. D-Sorbitol production was favored by low D-glucose concentrations $(<10$ wt $\%)$, high $\mathrm{H}_{2}$ pressures $(>40$

bar), and low reaction temperatures $\left(<140{ }^{\circ} \mathrm{C}\right)$, which suppressed undesired polymerization side reactions.

KEYWORDS: glucose, hydrogenation, platinum, sorbitol, SBA-15

\section{INTRODUCTION}

Carbohydrates derived from lignocellulosic biomass waste, such as agricultural or forestry residues and the organic fraction of municipal solid waste, are an attractive source of biogenic carbon from which sustainable biofuels and platform chemicals can be derived. ${ }^{1-5}$ In 2004, D-sorbitol was identified as 1 of the 12 most-important value-added chemicals obtainable from biomass by the U.S. Department of Energy, as a potential source of alkanes for liquid biofuels, or as an "outstanding building block for commodity chemicals", notably through its dehydration to isosorbide. ${ }^{6,7}$ Esters and derivatives of D-sorbitol also represent important additives and intermediates in the cosmetics and pharmaceuticals sectors, with the molecule being a key sugar substitute in the food and beverage industry, with an annual global production of $\sim 800000$ tons. ${ }^{6,7}$

D-Sorbitol is commonly obtained through the transitionmetal-catalyzed hydrogenation of D-glucose, ${ }^{8}$ notably over $\mathrm{Ni},{ }^{9-12} \mathrm{Ru},{ }^{13-17} \mathrm{Pt},{ }^{18}$ and $\mathrm{Rh}^{10}$ supported on oxides, carbons, polymers, hydrotalcites and zeolites. Commercial processes typically employ either Raney nickel or carbon-supported $\mathrm{Ru}$ catalysts; however, the former offers relatively poor selectivity and are prone to progressive on-stream deactivation and product contamination, ${ }^{12}$ whereas the latter is expensive and susceptible to poisoning by strongly bound organic impurities or sulfur compounds. ${ }^{19}$ Obviously, the existence of a commercial catalytic process must not preclude the pursuit of further process improvements and advancement of fundamental scientific knowledge; hence, studies have explored the role

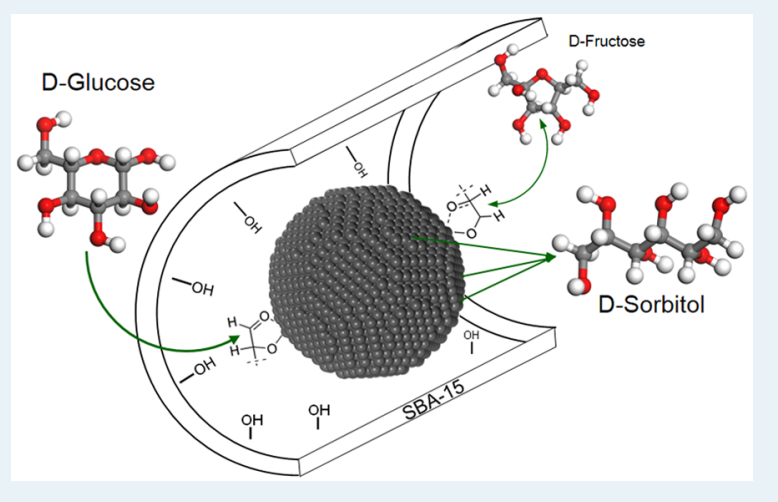

of basic supports, or poorly reduced active phases, in promoting
the Canizzaro side reaction and concomitant gluconic acid formation, ${ }^{20}$ which is a possible contributor to the deactivation of $\mathrm{Ni}$ and $\mathrm{Ru}$ catalysts. ${ }^{21}$ The influence of dopants to improve activity and selectivity, ${ }^{11}$ such as $\mathrm{Ru}-\mathrm{B},{ }^{22} \mathrm{Ni}-\mathrm{P}^{23}$ and $\mathrm{Co}-\mathrm{B},{ }^{24}$ has also been exploited; however, the resulting catalysts possess low surface areas and poor thermal stability, underperforming Raney nickel in industrial application. Pt nanocatalysts are generally more reducible and offer greater stability under hydrothermal reaction conditions than $\mathrm{Ni}$ or $\mathrm{Ru}$, as well as exhibit excellent performance in hydrogenation and hydroisomerization reactions. ${ }^{25-27}$ Gallezot et al. demonstrated continuous glucose hydrogenation to sorbitol in high yields over $\mathrm{Ru} / \mathrm{C},{ }^{17}$ but employed high $\mathrm{H}_{2}$ pressures (80 bar) and a $40 \mathrm{wt} \%$ glucose solution more concentrated than likely to be available from biorefineries through, e.g., steam explosion, wherein the resulting hydrolysate and condensate consist of $\sim 1-10$ wt $\%$ glucose ${ }^{28}$ and $8-15$ g of catalyst charges in the fixed bed. Sorbitol yields from $\mathrm{Ru}$ supported on alumina and titania are far lower in batch, typically $20 \%-60 \%$, even at 120 bar hydrogen. ${ }^{12}$ In contrast, Perrard and co-workers ${ }^{18}$ reported 10 wt \% Pt/C catalysts operating at $100{ }^{\circ} \mathrm{C}$ and 80 bar $\mathrm{H}_{2}$ pressure with a specific activity of $1800 \mathrm{mmol} \mathrm{g}_{\mathrm{Pt}}^{-1} \mathrm{~h}^{-1}$ and selectivity $>99.5 \%$ to $\mathrm{D}$-sorbitol. Hydrotalcite addition to the

Received: August 18, 2016

Revised: September 22, 2016

Published: September 26, 2016 
reaction medium dramatically enhanced both glucose hydrogenation and concomitant sorbitol production over a $3.5 \mathrm{wt} \%$ $\mathrm{Pt} / \mathrm{Al}_{2} \mathrm{O}_{3}$ catalyst, attributed to enhancement of the openchain-form glucose under alkaline conditions. ${ }^{29}$ The only direct comparative studies of glucose hydrogenation over low loading $\mathrm{Ru}$ and $\mathrm{Pt}$ on activated carbon reported identical activities between the two metals in both batch and flow operation, but superior sorbitol selectivity for platinum in all cases. ${ }^{30,31}$ Unfortunately, none of the preceding studies employed reaction conditions free from mass-transport limitations or reported carbon mass balances, prohibiting reliable and quantitative assessment of the influence of either catalyst properties or operating conditions, or comparisons between catalysts.

Despite the potential significance of Pt-catalyzed carbohydrate hydrogenation ${ }^{32-35}$ for biorefining, the aqueous phase hydrogenation of D-glucose to D-sorbitol therefore remains poorly understood, with no systematic studies into the reaction network or structure sensitivity, or performance benchmarking of intrinsic reaction rates. Here, we report the first fundamental investigation into structure-activity relationships for aqueousphase glucose hydrogenation by any family of well-defined and systematically related catalysts, identifying strong particle size and support effects for silica-supported Pt catalysts. Such insight will prove valuable for the development of more robust, active and selective catalysts for the overall hydrolytic hydrogenation of cellulose to sugar alcohols, ${ }^{36}$ which is an important route to improve the efficiency of biomass conversion to platform chemicals and fuels. ${ }^{37,38}$

\section{EXPERIMENTAL SECTION}

2.1. Catalyst Synthesis. Two families of fumed silica and SBA-15-supported Pt catalysts were prepared by wet impregnation. ${ }^{39}$ Typically, $2.5 \mathrm{~g}$ of the support (SBA-15 or fumed silica) was contacted with $25 \mathrm{~mL}$ of aqueous ammonium tetrachloroplatinate(II) solution with the metal precursor concentration adjusted to achieve nominal Pt loadings spanning $0.05-2 \mathrm{wt} \%$. Slurries were stirred for $18 \mathrm{~h}$ overnight at room temperature, and subsequently evaporated to dryness at $80^{\circ} \mathrm{C}$ under agitation. The resulting powders were calcined at $550{ }^{\circ} \mathrm{C}$ for $2 \mathrm{~h}$ under static air in a muffle furnace $\left(\right.$ ramp rate $=1{ }^{\circ} \mathrm{C}$ $\left.\mathrm{min}^{-1}\right)$, followed by reduction at $400{ }^{\circ} \mathrm{C}$ for $2 \mathrm{~h}$ (ramp rate $=$ $\left.10^{\circ} \mathrm{C} \mathrm{min}^{-1}\right)$ under flowing $\mathrm{H}_{2}\left(10 \mathrm{~mL} \mathrm{~min}{ }^{-1}\right)$. Catalysts were stored under ambient conditions and used for reactions without further treatment.

2.2. Catalyst Characterization. Nitrogen porosimetry was undertaken on a Quantachrome Nova 4000e porosimeter and analyzed with NovaWin software, Version 11. Samples were degassed in vacuo at $120{ }^{\circ} \mathrm{C}$ for $2 \mathrm{~h}$ prior to measurement of nitrogen adsorption/desorption isotherms at $-196{ }^{\circ} \mathrm{C}$. Brunauer-Emmett-Teller (BET) surface areas were calculated over the relative pressure range of $0.01-0.2$. Pore diameters and volumes were calculated by applying the Barrett-JoynerHalenda (BJH) method to desorption isotherms for relative pressures of $>0.35$. Low- and wide-angle XRD patterns were recorded on a diffractometer (Bruker, Model D8 Advance) fitted with a LYNXeye detector and $\mathrm{Cu} \mathrm{K} \alpha(1.54 \AA)$ calibrated against a corundum standard. Low-angle patterns were recorded from $2 \theta=0.45^{\circ}-8^{\circ}$ with a step size of $0.01^{\circ}$, and wide angle patterns from $2 \theta=10^{\circ}-80^{\circ}$ with a step size of $0.02^{\circ}$. The Scherrer equation was used to calculate volumeaveraged $\mathrm{Pt}$ crystallite diameters from broadening of the associated face-centered cubic (fcc) metal reflections. XPS was performed on a Kratos Axis HSi X-ray photoelectron spectrometer fitted with a charge neutralizer and magnetic focusing lens, employing $\mathrm{Al} \mathrm{K} \alpha$ monochromatic radiation $(1486.7 \mathrm{eV})$. Spectral fitting was performed using CasaXPS version 2.3.14. Binding energies were corrected to the $\mathrm{C} 1 \mathrm{~s}$ peak at $284.6 \mathrm{eV}$, and surface atomic compositions were calculated via correction for the appropriate instrument response factors. $\mathrm{Pt}_{4 \mathrm{f}} \mathrm{XP}$ spectra were fitted using a Doniach Sunjic modified Gaussian-Lorentzian asymmetric line shape. $\mathrm{Pt}$ dispersions were measured via $\mathrm{CO}$ pulse chemisorption on a Quantachrome ChemBET 3000 system. Samples were outgassed at $150{ }^{\circ} \mathrm{C}$ under flowing helium $\left(20 \mathrm{~mL} \mathrm{~min}^{-1}\right)$ for $1 \mathrm{~h}$, prior to reduction at $150{ }^{\circ} \mathrm{C}$ under flowing hydrogen $(10 \mathrm{~mL}$ $\mathrm{min}^{-1}$ ) for $1 \mathrm{~h}$ before room-temperature analysis in order to remove any surface oxide formed during storage; this reduction protocol is milder than the $400{ }^{\circ} \mathrm{C}$ reduction employed in catalyst synthesis, and it does not induce particle sintering and, hence, avoids distortion of the true $\mathrm{Pt}$ dispersion in the asprepared catalyst. A CO:Pt surface stoichiometry of 0.68 was assumed, ${ }^{40,41}$ since the formation of a fully saturated monolayer is energetically unfavorable, under the measurement conditions employed. Powder X-ray diffraction (XRD) and transmission electron microscopy (TEM) on spent catalysts revealed no evidence of in situ particle sintering during the liquid-phase hydrogenation of D-glucose under our (relatively mild) standard reaction conditions of 40 bar and $140{ }^{\circ} \mathrm{C}$. Scanning transmission electron microscopy (STEM) was conducted on an aberration-corrected electron microscope (JEOL, Model 2100-F) operating at $200 \mathrm{kV}$, with mean Pt particle sizes determined from a minimum of 100 particles. Elemental analysis of the bulk $\mathrm{Pt}$ content of digested samples was measured by inductively coupled plasma-optical emission spectroscopy (ICP-OES), using a Varian Vista MPX instrument (MEDAC, Ltd.).

2.3. D-Glucose Hydrogenation. D-Glucose hydrogenation was performed in a $50 \mathrm{~mL}$ stainless steel Parr autoclave, using $40 \mathrm{~mL}$ of a 2.5 wt \% D-glucose aqueous solution, typically at $140{ }^{\circ} \mathrm{C}$ and 40 bar $\mathrm{H}_{2}$ pressure. Reactions were performed for 4 $\mathrm{h}$ under stirring at $900 \mathrm{rpm}$ (which tests confirmed was sufficient to eliminate external mass-transport limitations (see Figure $\mathrm{S} 6 \mathrm{c}$ in the Supporting Information). In a typical protocol, $0.2 \mathrm{~g}$ of catalyst was added to the reaction mixture and the reactor purged with $\mathrm{N}_{2}$ three times to remove oxygen, and an aliquot was removed. The reaction mixture was subsequently heated to the target temperature under $\mathrm{N}_{2}$ and immediately sampled again to assess whether significant reaction occurred during the $(\sim 20 \mathrm{~min})$ heating process. Finally, the autoclave was filled to a constant $\mathrm{H}_{2}$ pressure, maintained from an external manifold, and aliquots were periodically removed via a dip-tube inserted into the solution, filtered to remove the catalyst, and then analyzed without dilution by a 1200 Infinity Series Agilent Technologies HPLC equipped with a refractive index detector and Hi-Plex Ca-Duo column at $80{ }^{\circ} \mathrm{C}$, using a pure water mobile phase at $0.6 \mathrm{~mL}$ $\mathrm{min}^{-1}$. Analyses were performed in triplicate, with a peak area reproducibility of $\pm 2 \%$ for D-glucose, D-fructose, and D-sorbitol, and $\pm 10 \%$ for D-mannitol, because of its extremely low yield. Response factors for D-glucose, D-mannose, D-fructose, Dmannitol, and D-sorbitol were determined from respective multipoint calibration curves. D-glucose conversion, product selectivity and yield, and carbon mass balances were calculated according to eqs $1-4$ : 



Figure 1. Influence of (a) Pt particle size and (b) surface Pt content from XPS with bulk Pt loading over $\mathrm{SiO}_{2}$ and SBA-15 supports.

$$
\begin{aligned}
& \text { conversion (\%) } \\
& =\frac{\text { (number of moles of glucose } e_{t=0}-\text { number of moles of glucose } e_{t=i} \text { ) }}{\text { number of moles of glucose } e_{t=0}} \\
& \times 100
\end{aligned}
$$



$$
\begin{aligned}
& \times 100 \\
& \text { yield }(\%)=\frac{\text { number of moles of product }}{\text { number of moles of glucose }} \underset{t=0}{ } \times 100 \\
& \text { mass balance }(\%)=\frac{\text { total number of moles of carbon in all products }}{\text { number of moles of carbon in converted glucose }} \\
& \times 100
\end{aligned}
$$

Initial rates of $\mathrm{D}$-glucose conversion and $\mathrm{D}$-sorbitol production were determined at low conversion $(<25 \%)$ from the linear portion of reaction profiles (i.e., in the absence of mass-transport limitations or catalyst deactivation) and used to calculate the turnover frequencies (TOFs) for D-glucose conversion and D-sorbitol productivity, based on the number of surface $\mathrm{Pt}$ atoms determined by $\mathrm{CO}$ chemisorption. Initial rates of D-fructose, D-mannitol, and D-sorbitol conversion as reactants were similarly determined at low conversion $(<25 \%)$. Selectivities are reported at iso-conversion levels of $\sim 5 \%$, unless otherwise specified.

\section{RESULTS AND DISCUSSION}

3.1. Catalyst Characterization. The successful genesis of Pt impregnated SBA-15 having an ordered hexagonal-closepacked (hcp) mesoporous network was confirmed by low-angle XRD and nitrogen porosimetry (see Figure $S 1$ in the Supporting Information). Three well-resolved reflections at $2 \theta=0.96^{\circ}, 1.57^{\circ}$, and $1.8^{\circ}$, characteristic of the (100), (110), and (200) planes of the $p 6 \mathrm{~mm}$ symmetry SBA-15 support architecture, were visible in both the parent and Pt-functionalized materials. Nitrogen porosimetry showed the expected Type IV isotherm with an $\mathrm{H} 1$ hysteresis loop, characteristic of SBA-15 for all Pt loadings, with a common mean BJH pore diameter of $6.7 \mathrm{~nm}$, indicating that silica mesoporous channels remained unblocked following $\mathrm{Pt}$ impregnation. $\mathrm{Pt} /$ fumed silicas prepared from a commercial amorphous support exhibited a Type II $\mathrm{N}_{2}$ adsorption isotherm, consistent with a low surface area nonporous or macroporous material. BET surface areas for both silica families decreased as the Pt loading increased, with the Pt/SBA-15 samples exhibiting the greatest losses (up to $15 \%$ ), compared with the parent support. Pore volumes of SBA-15 also declined slightly with increasing Pt loading, which we attribute to partial blockage of micropores within the mesopore walls. ${ }^{18}$ It is important to note that these small decreases indicate that the majority of mesopore channels and entrained $\mathrm{Pt}$ nanoparticles remain fully accessible to reactants; porosimetry (an averaging methodology not susceptible to the selective bias inherent in spatially localized electron microscopy) confirms that SBA-15 mesopores were not blocked by Pt. The small decrease in surface areas for the $\mathrm{Pt} /$ fumed silica samples was consistent with the deposition of Pt nanoparticles predominantly over the external surface area of the amorphous support (see Table S1 in the Supporting Information).

Wide-angle XRD patterns of SBA-15 and commercial $\mathrm{SiO}_{2}$ families of Pt catalysts show reflections at $2 \theta=39.8^{\circ}, 46.4^{\circ}$, and $67.6^{\circ}$ (see Figure S2 in the Supporting Information), which are associated with the (111), (200), and (220) facets, respectively, of fcc Pt metal. The decrease in the full width at half maximum (fwhm) of these reflections with Pt loading is indicative of a concomitant increase in Pt cluster size for both supports, quantified by Scherrer analysis (Figure 1a). Generally, the higharea SBA-15 support favors smaller $\mathrm{Pt}$ particle sizes (and correspondingly higher dispersions from $\mathrm{CO}$ chemisorption; see Figure S3 in the Supporting Information) for a given metal loading than the fumed silica, with values in excellent agreement with those measured by STEM (see Tables S1 and S2 and Figure S4 in the Supporting Information): the average $\mathrm{Pt}$ particle size varied over a range of $3.8-10.5 \mathrm{~nm}$ for Pt/SBA-15 and 3.4-16.6 nm for Pt/fumed silica. $\mathrm{Pt}_{4 \mathrm{f}} \mathrm{XPS}$ spectra of the Pt/SBA-15 series (Figure S5 in the Supporting Information) revealed a monotonic increase in surface $\mathrm{Pt}$ concentration with bulk Pt loading, as shown in Figure $1 \mathrm{~b}$. Corresponding $\mathrm{Pt}$ surface concentrations for the $\mathrm{Pt} /$ fumed silica family mirror those for the SBA-15 support for bulk Pt loadings of $\leq 0.4 \mathrm{wt} \%$, above which they attained a plateau consistent with the formation of the large three-dimensional (3D) Pt crystallites observed by XRD. Peak fitting of both Pt/ SBA-15 and Pt/fumed silica families demonstrated that platinum was predominantly present in metallic form (compositions spanning 80\%-95\% $\mathrm{Pt}^{0}$ ) for all loadings.

3.2. D-Glucose Hydrogenation. 3.2.1. Structure-Activity Relationships. The influence of Pt particle size on the aqueous phase hydrogenation of D-glucose was initially investigated 



Figure 2. Influence of Pt particle size on (a) sorbitol productivity and (b) sorbitol turnover frequency (TOF) during aqueous phase glucose hydrogenation over silica and SBA-15 supports at $140{ }^{\circ} \mathrm{C}$ and 40 bar.

under $140{ }^{\circ} \mathrm{C}$ and 40 bar (conditions favoring good hydrogenation activity and D-sorbitol formation as discussed later, and under which the catalyst charge and agitation rates were chosen to ensure freedom from mass-transport limitations (see Figures S6a-c in the Supporting Information). Activities for D-glucose conversion (Figure S7a in the Supporting Information) were inversely proportional to $\mathrm{Pt}$ particle size, i.e., rate $\propto$ diameter $^{-y}$, with proportionality constants $y>1$ over both supports, indicating that the rate of $\mathrm{D}$-glucose conversion is not directly correlated with the geometric surface $\mathrm{Pt}$ atom density (i.e., at least one of the possible reaction pathways for $D$ glucose is structure-sensitive). The highest specific activities for Dglucose conversion of 1 and $1.5 \mathrm{~mol} \mathrm{~g}_{\mathrm{Pt}}{ }^{-1} \mathrm{~h}^{-1}$, observed for the smallest $(3.4 \mathrm{~nm}) \mathrm{Pt}$ particles on $\mathrm{SiO}_{2}$ and SBA-15, respectively, are in good agreement with that reported at 100 ${ }^{\circ} \mathrm{C}$ but a significantly higher $\mathrm{H}_{2}$ pressure ( 80 bar) for $4 \mathrm{~nm} \mathrm{Pt}$ particles on activated carbon cloth, ${ }^{18}$ and significantly higher than that reported by Gallezot et al. $\left(342 \mathrm{mmol} \mathrm{g}_{\mathrm{Ru}}{ }^{-1} \mathrm{~h}^{-1}\right)$ over 1.8 wt $\% \mathrm{Ru}$ on activated carbon extrudates. ${ }^{17}$ Note that the literature on metal-catalyzed glucose hydrogenation is dominated by an inappropriate focus on sorbitol yield (\%), which is a very poor measure of catalyst performance, since it is entirely dependent on the reaction conditions that are chosen (particularly catalyst:substrate ratio and time scale of reaction) and, hence, is not a transferable parameter between studies. DSorbitol productivity, expressed in terms of either mmol $\mathrm{g}_{\text {metal }}{ }^{-1}$ time $^{-1}$ or turnover frequency (TOF) per amount of metal, is a far more meaningful parameter for catalyst comparison.

The primary products from D-glucose were D-fructose and Dsorbitol over all catalysts, with D-fructose productivity semiquantitatively mirroring the $\mathrm{Pt}$ size dependence of D-glucose conversion (see Figure S7b in the Supporting Information), suggesting that isomerization of the latter is the dominant process under these initial reaction conditions, and that $\mathrm{Pt}$ is structure-sensitive for this transformation (possibly catalyzed by Lewis acid $\mathrm{Pt}^{\delta+}$ sites present on smaller particles). In contrast, while D-sorbitol productivity was likewise inversely proportional to Pt particle size, the proportionality constants $y$ were close to unity over both supports (Figure 2a), as would be anticipated if $\mathrm{D}$-sorbitol production was dependent solely on the geometric $\mathrm{Pt}$ surface area, i.e., if $D$-glucose hydrogenation to D-sorbitol is structure-insensitive. This hypothesis was confirmed by calculating the TOFs for D-sorbitol production (normalized to the surface Pt metal), which Figure $2 \mathrm{~b}$ reveals as both support and particle size invariant across the particle size range investigated.
Our observed TOFs of 45-60 $\mathrm{h}^{-1}$ are in good agreement with the literature values reported for $\mathrm{Pt} / \mathrm{Al}_{2} \mathrm{O}_{3}\left(54 \mathrm{~h}^{-1}\right)^{29}$ and $\mathrm{Ru} /$ $\mathrm{SiO}_{2}\left(75 \mathrm{~h}^{-1}\right) .^{42}$

The preceding results indicate that $\mathrm{D}$-glucose isomerization to $\mathrm{D}$-fructose is favored over low-coordination $\mathrm{Pt}^{\delta+}$ sites, which XPS fitting reveals are more prevalent on smaller particles (see Figure S8 in the Supporting Information), whereas sorbitol formation is structure-insensitive; hence, selectivity toward these products is expected to exhibit a particle size dependence at iso-conversion. Figure 3 confirms this prediction, with D-



Figure 3. Influence of Pt particle size on sorbitol and fructose relative product selectivity during aqueous phase glucose hydrogenation over silica and SBA- 15 supports at $140{ }^{\circ} \mathrm{C}$ and 40 bar. Selectivities calculated at $5 \%$ glucose conversion.

sorbitol selectivity rising approximately linearly with Pt particle size (and loading) at the quantitative expense of $D$-fructose over both supports, consistent with competing reaction pathways. Recycle tests, performed on the 1.5 wt \% catalyst without any reactivation protocols, demonstrated good stability, with $75 \%$ of sorbitol productivity being retained upon reuse; the slight activity loss is attributed to carbon deposition, with CHNS revealing $\sim 3$ wt \% carbon in the spent catalyst, likely arising from strongly adsorbed oligomers of reactively formed fructose $^{43}$ or associated 5-hydroxymethylfurfural (5-HMF). ${ }^{44}$ The issue of catalyst stability during glucose hydrogenation is very rarely addressed in literature reports, and in all but one case (the study by Sapunov et al. ${ }^{16}$ ), quantitative comparison is, in any event, hindered by (i) the failure to report mass balances; and (ii) the decision to operate under forcing reaction 
Table 1. Comparison and Limitations of Representative Metal-Catalyzed D-Glucose Hydrogenation ${ }^{a}$

\begin{tabular}{|c|c|c|c|c|c|}
\hline catalyst & $\begin{array}{l}\text { first cycle conversion } \\
\text { or yield }{ }^{b}(\%)\end{array}$ & recycle & $\begin{array}{l}\text { carbon mass } \\
\text { balance }\end{array}$ & reaction conditions & ref \\
\hline $\begin{array}{l}\mathrm{Ru} / \text { mesoporous carbon } \\
\text { microfibers }\end{array}$ & NR & stable over 5 cycles & NR & $\begin{array}{l}40 \text { wt } \% \text { glucose, } 0.05 \text { g catalyst, } 100{ }^{\circ} \mathrm{C}, 80 \\
\text { bar, } 3 \mathrm{~h}, 1000 \mathrm{rpm}, 30 \mathrm{~mL}\end{array}$ & 13 \\
\hline $\mathrm{Ru} / \mathrm{MCM}-41$ & $>97$ & $15 \%$ sorbitol yield loss after 1 cycle & NR & $\begin{array}{l}10 \text { wt } \% \text { glucose, } 0.25 \mathrm{~g} \text { catalyst, } 120^{\circ} \mathrm{C}, 30 \\
\text { bar, } 3 \mathrm{~h}, 500 \mathrm{rpm}, 25 \mathrm{~mL}\end{array}$ & 15 \\
\hline $\mathrm{Ru} /$ polystyrene & 41 & stable over 10 cycles & NR & $\begin{array}{l}29 \mathrm{wt} \% \text { glucose, } 0.4 \mathrm{~g} \text { catalyst, } 100{ }^{\circ} \mathrm{C}, 40 \mathrm{bar} \text {, } \\
1.33 \mathrm{~h}, 50 \mathrm{~mL}\end{array}$ & 16 \\
\hline 1 wt $\% \mathrm{Ru} / \mathrm{HY}$ & $>95$ & $\begin{array}{l}\sim 5 \% \text { activity loss after } 1 \text { recycle. TEM } \\
\text { evidenced aggregation }\end{array}$ & NR & $\begin{array}{l}25 \text { wt \% glucose, } 1 \text { g catalyst, } 120^{\circ} \mathrm{C}, 55 \mathrm{bar} \text {, } \\
0.33 \mathrm{~h}, 1200 \mathrm{rpm}, 160 \mathrm{~mL}\end{array}$ & 14 \\
\hline $\mathrm{Ru} / \mathrm{ZSM}-5-\mathrm{TF}$ & $>95$ & $\begin{array}{l}\sim 5 \%-20 \% \text { sorbitol yield loss after } 1 \\
\text { recycle }\end{array}$ & NR & $\begin{array}{l}25 \text { wt \% glucose, } 0.5 \text { g catalyst, } 120^{\circ} \mathrm{C}, 40 \mathrm{bar}, \\
2 \mathrm{~h}, 500 \mathrm{rpm}, 50 \mathrm{~mL}\end{array}$ & 45 \\
\hline $\mathrm{Ru}(1 \%) / \mathrm{NiO}(5 \%)-\mathrm{TiO}_{2}$ & $>93$ & NR & NR & $\begin{array}{l}20 \text { wt } \% \text { glucose, } 120{ }^{\circ} \mathrm{C}, 55 \text { bar, } 2 \mathrm{~h} \text {, } \\
1200 \mathrm{rpm}\end{array}$ & 46 \\
\hline 5 wt \% Pt/charcoal & $>94$ & $5 \%$ sorbitol yield loss after 5 recycles & NR & $\begin{array}{l}25-65{ }^{\circ} \mathrm{C}, 1 \mathrm{bar}, 10 \mathrm{wt} \% \text { glucose, } 12 \text { wt } \% \\
\text { catalyst }\end{array}$ & 47 \\
\hline Pt-PEI nanoparticles & 100 & NR & "poor" & $\begin{array}{l}0.48 \mathrm{~g} \text { glucose, } 60 \mathrm{~g} \text { water, } 1 \mathrm{~g} \text { Pt-PEI } \\
\text { dispersion, } 50 \text { bar } \mathrm{H}_{2}, 3 \mathrm{~h}, 180^{\circ} \mathrm{C}\end{array}$ & 48 \\
\hline $1 \mathrm{wt} \% \mathrm{Pt} / \mathrm{AC}$ & $>95$ & NR & NR & $\begin{array}{l}2.8 \text { wt } \% \text { glucose, } 0.06 \mathrm{~g} \text { catalyst, } 180{ }^{\circ} \mathrm{C}, 16 \\
\text { bar, } 3 \mathrm{~h}, 1100 \mathrm{rpm}, 5 \mathrm{~mL}\end{array}$ & 30 \\
\hline 10 wt $\% \mathrm{Pt} / \mathrm{AC}$ cloth & $\sim 100$ & NR & NR & $\begin{array}{l}40 \text { wt \% glucose, } 100^{\circ} \mathrm{C}, 80 \text { bar, catalyst mass } \\
\text { unreported }\end{array}$ & 18 \\
\hline $\begin{array}{l}\mathrm{Pt} / \gamma-\mathrm{Al}_{2} \mathrm{O}_{3}+0.075 \mathrm{~g} \\
\quad \text { hydrotalcite }\end{array}$ & 100 & $\begin{array}{l}20 \% \text { activity loss after } 1 \text { cycle; } 12 \% \\
\text { loss after second }\end{array}$ & $\sim 93 \%$ & $\begin{array}{l}0.4 \text { wt } \% \text { glucose, } 0.075 \mathrm{~g} \text { catalyst, } 90{ }^{\circ} \mathrm{C}, 16 \\
\text { bar, } 4 \mathrm{~h}, 700 \mathrm{rpm}, 35 \mathrm{~mL}\end{array}$ & 29 \\
\hline
\end{tabular}

Scheme 1. (a) Ring Opening and Hydrogenation of D-Glucose, and (b) Proposed Isomerization of D-Glucose to D-Fructose over Low Coordination Sites of Pt Nanoparticles
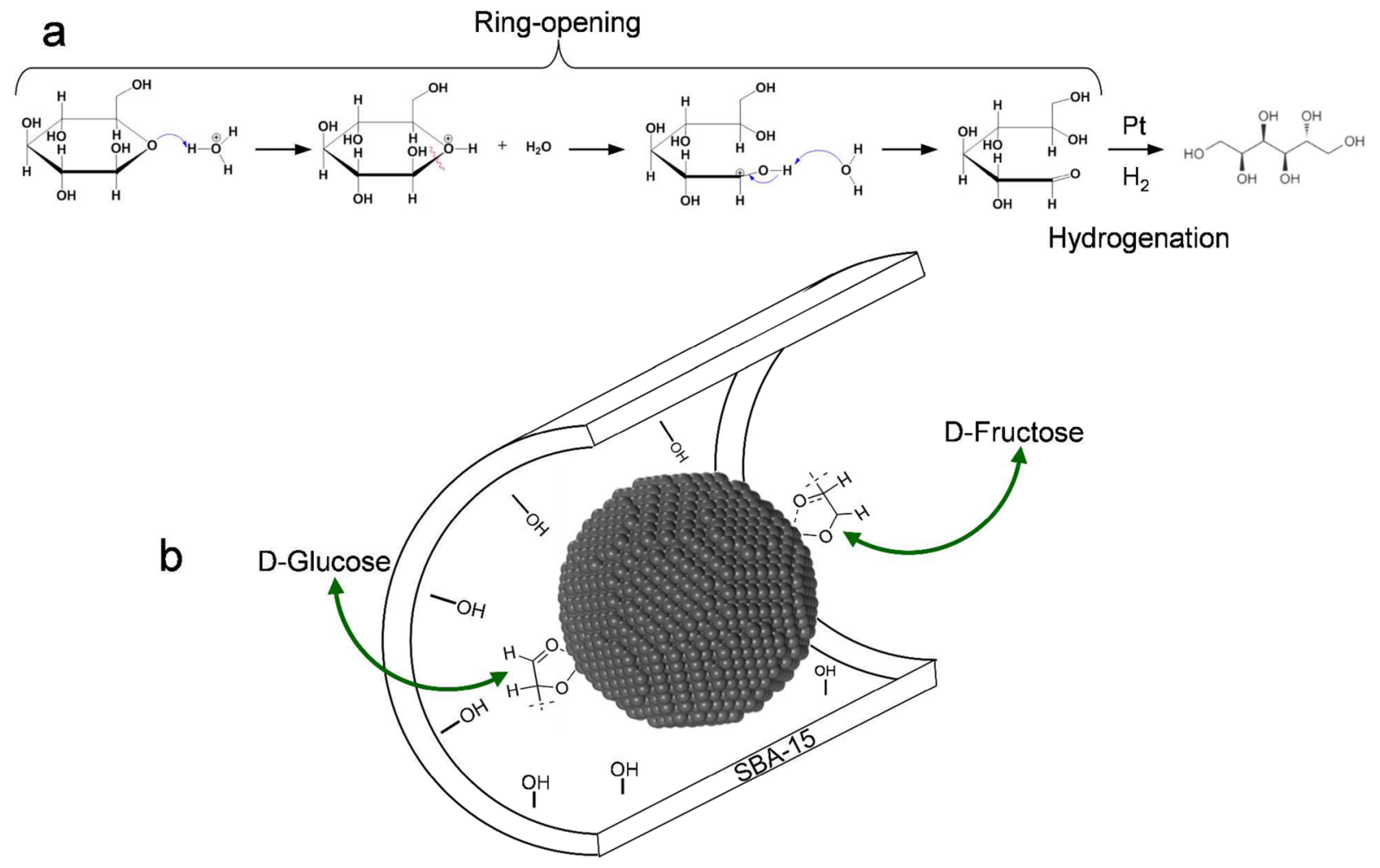

conditions with a view to achieving complete glucose conversion/high sorbitol yields, the wrong regime in which to assess deactivation (Table 1) since reactions are limited by mass transport (and susceptible to product inhibition), rather than being limited by reaction rate.

The superior D-sorbitol selectivity of larger Pt nanoparticles was independent of conversion (see Figure S9 in the Supporting Information), in contrast to smaller particles, wherein selectivity decreased with conversion, suggesting that selective sites within the latter may be lost through reactioninduced restructuring or self-poisoning by reactively formed adsorbates.

An understanding of the competing pathways leading to Dsorbitol or $\mathrm{D}$-fructose production requires consideration of the factors affecting the conformation of the D-glucose substrate. Dglucose exists in water as a 2:1 ratio of the $\beta$-anomer or $\alpha$ anomer, with only $\sim 0.0026 \mathrm{~mol} \%$ present as the aldose or ketose open chain forms. ${ }^{49} \mathrm{D}$-sorbitol is only produced from the 
Scheme 2. Reaction Network for D-Glucose and D-Fructose Hydrogenation over 1.5 wt \% Pt/SBA-15 at $140{ }^{\circ} \mathrm{C}$ and 40 bar $\mathrm{H}_{2}$

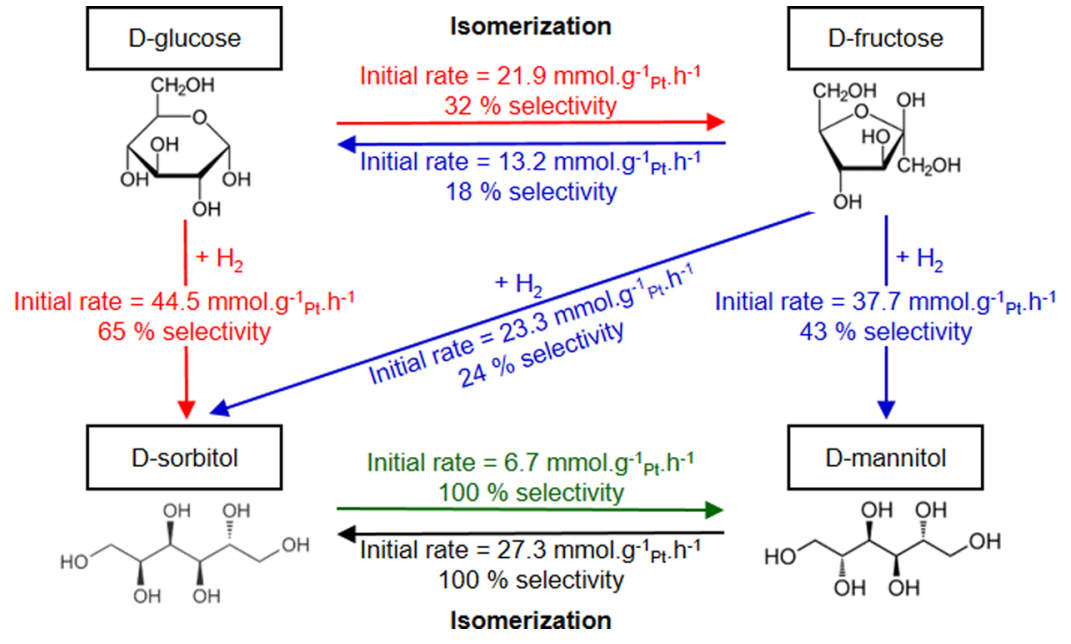

aldose form, attained via proton transfer to the ether-O of the glucopyranose ring and subsequent $\mathrm{C}(1)-\mathrm{O}(5)$ bond scission (generally considered to be the rate-limiting step in forming the open chain aldose conformation shown in Scheme 1a). While the precise mechanism remains under debate, DFT calculations suggest that this conformational change initiates in water via deprotonation of the anomeric hydroxyl group, followed by proton transfer to the ring ether-O atom. ${ }^{50,51}$ The aldehyde function of the aldose conformer may adsorb on metal surfaces via either the oxygen lone pair $\eta_{\mathrm{O}}^{1}$ or carbonyl $\eta_{\mathrm{C}=\mathrm{O}}^{2}$ configurations. The latter configuration is favored for allylic aldehydes such as cinnamaldehyde or crotonaldehyde over (111) facets of large $\mathrm{Pt}$ particles, promoting $\mathrm{C}=\mathrm{O}$ bond activation and hydrogenation, ${ }^{52-55}$ whereas low coordination (100) and (110) sites prevalent on particles $<2 \mathrm{~nm}$ promote decarbonylation and concomitant $\mathrm{CO}$ self-poisoning. ${ }^{53}$ The observed selectivity dependence for D-glucose hydrogenation to D-sorbitol is consistent with these principles, with larger $\mathrm{Pt}$ nanoparticles possessing a higher density of (111) facets and, hence, hydrogenation of the $\mathrm{C}=\mathrm{O}$ group within the aldose conformer. The higher $\mathrm{D}$-fructose selectivity of smaller $\mathrm{Pt}$ nanoparticles may result from preferential coordination of the more weakly bound $\eta^{1}$ o configuration to electron-deficient Lewis acid sites (known to catalyze D-glucose isomerization ${ }^{56}$ ) present over small Pt nanoparticles, which XPS shows possess a higher surface density of $\mathrm{Pt}^{\delta+}$ species. DFT calculations also suggest isomerization may be promoted via hydrogen bonding to surface hydroxyls ${ }^{57}$ present at the $\mathrm{Pt} /$ silica interface. Models of glucose interacting with single $\mathrm{Pt}$ atoms on single-walled carbon nanotubes show the sugar coordinates via the $\mathrm{O}$ atom of the $-\mathrm{C}(6) \mathrm{H}_{2} \mathrm{OH}$ through charge transfer from glucose to $\mathrm{Pt}^{58}$ (Scheme 1b).

In light of the inverse correlation between D-fructose and Dsorbitol production during glucose conversion, the question arises as to whether the latter is formed by the direct hydrogenation of (the aldose conformer of) glucose or an isomerized $\mathrm{D}$-fructose intermediate. Hence, the reactivity of the most selective $1.5 \mathrm{wt} \% \mathrm{Pt} / \mathrm{SBA}-15$ catalyst toward D-fructose hydrogenation, and the hydro-isomerization of mannitol and sorbitol at $140{ }^{\circ} \mathrm{C}$ and 40 bar $\mathrm{H}_{2}$ was therefore explored subsequently. Whereas D-glucose proceeds almost exclusively to D-sorbitol and D-fructose with $69 \%$ and 30\% selectivity, respectively (Figure S10a in the Supporting Information), Dmannitol was the major product of $\mathrm{D}$-fructose hydrogenation
(Figure S10b), with only $24 \%$ selectivity to D-sorbitol. Dfructose isomerization to D-glucose, and dehydration to 5-HMF were also observed. The overall reaction network for D-glucose hydrogenation, and of the key products/reactive intermediates, is summarized in Scheme 2, with the associated rates representing the first intrinsic kinetic parameters for Ptcatalyzed glucose hydrogenation, free from mass transport limitations. Negligible hydro-isomerization of D-sorbitol and Dmannitol occurred over our Pt catalysts, with only $6 \%$ and $3 \%$ converted, respectively, after $4 \mathrm{~h}$ of reaction; hence, neither would be anticipated to undergo interconversion if formed during D-glucose hydrogenation. The superior rate (and selectivity) for D-sorbitol formation from D-glucose, in comparison to that for D-mannitol formation from D-fructose, may reflect more sterically demanding surface constraints associated with the hydrogenation of the latter ketose conformer (versus the aldose conformer). DFT calculations suggest that aldehyde (propanal) hydrogenation should be favored, relative to ketone (acetone) hydrogenation, over $\operatorname{Pt}(111)$, because of the latter adopting the weaker $\eta_{\mathrm{O}}^{1}$ adsorption configuration. ${ }^{59}$ Consistent with this hypothesis, Heinen et al. proposed that the furanose form of fructose binds more weakly than the aldose form of D-glucose, ${ }^{32}$ in accordance with our observations for their different rates of hydrogenation.

3.2.2. Influence of Reaction Conditions. Reaction conditions were varied with a view toward shedding more insight into the reaction pathways and optimizing D-sorbitol production over the most selective 1.5 wt $\% \mathrm{Pt} / \mathrm{SBA}-15$ catalyst. Figure 4 shows the impact of reaction temperature on the rate of glucose conversion and product selectivity. Higher temperatures exponentially increased activity, but favored Dfructose over D-sorbitol, with selectivity to the latter desired product decreasing from $100 \%$ at $80{ }^{\circ} \mathrm{C}$ to a plateau of $\sim 55 \%$ at $>140{ }^{\circ} \mathrm{C}$ (see Figure S11a in the Supporting Information), a similar temperature-dependent decrease to that observed over $\mathrm{Pt} / \mathrm{C}^{31}$ The emergence of trace D-mannitol at the highest temperatures is consistent with a high activation barrier to Dfructose hydrogenation. It is important to note that the overall carbon mass balance decreases significantly at high temperatures (Figure S11b), indicating the occurrence of side reactions such as retro-aldols to form dihydroxyacetone, glycol aldehyde and formaldehyde, D-glucose dimerization, ${ }^{60}$ and polymerization to solid organic residues (humins). ${ }^{61,43}$ Such mass balances and byproduct formation are rarely reported or 




Figure 4. Influence of reaction temperature on the aqueous phase hydrogenation of D-glucose over $1.5 \mathrm{wt} \% \mathrm{Pt} / \mathrm{SBA}-15$ under 40 bar $\mathrm{H}_{2}$.

quantified accurately in the literature. Therefore, low reaction temperatures favor the selective hydrogenation of D-glucose over $\mathrm{Pt}$, with high temperatures promoting undesirable $\mathrm{D}$ glucose isomerization to fructose and concomitant polymerization and degradation pathways. The apparent activation energy for D-glucose hydrogenation $\left(47 \mathrm{~kJ} \mathrm{~mol}^{-1}\right.$; see Figure S12 in the Supporting Information) is in good agreement with that observed for $\mathrm{Ru} / \mathrm{C}\left(55 \mathrm{~kJ} \mathrm{~mol}^{-1}\right),{ }^{62}$ Raney nickel (44 kJ $\left.\mathrm{mol}^{-1}\right),{ }^{9}$ supported $\mathrm{Ni}\left(67 \mathrm{~kJ} \mathrm{~mol}^{-1}\right),{ }^{12}$ and over $\mathrm{Ru} / \mathrm{H}-\mathrm{Y}^{14}$ catalysts $\left(33 \mathrm{~kJ} \mathrm{~mol}^{-1}\right)$.

The rate of $\mathrm{D}$-glucose conversion was first-order, with respect to its concentration for dilute mixtures $<10 \mathrm{wt} \%$, deviating only slightly from linearity at higher concentration (Figure S13a in the Supporting Information). ${ }^{46}$ Although the selectivity to the principal D-sorbitol and D-fructose products was essentially independent of [D-glucose], mass balance decreased steeply with increasing substrate concentration (Figures S13b and S13c), which is consistent with the reports by Guo et al., ${ }^{22}$ and is likely associated with enhanced solution phase processes in competition with heterogeneous catalysis. Our observations are in good agreement with previous studies that suggest D-glucose hydrogenation follows Langmuir-Hinshelwood kinetics with first-order behavior for concentrations of $<25 \mathrm{wt} \%{ }^{24,62}$ with hydrogen dissociation uninhibited by a high $\mathrm{D}$-glucose surface coverage. The pressure dependence of $\mathrm{D}$-glucose conversion was also explored for $\mathrm{H}_{2}$ pressures spanning 5-60 bar (see Figure 5, as well as Figure S14 in the Supporting Information): activity increased more than 10 -fold as the pressure was initially increased from 5 to 10 bar, exhibiting a slower dependence on pressure between 10 and 40 bar $\mathrm{H}_{2}$. The reaction order in $p_{\mathrm{H}_{2}}$ of 0.66 was in reasonable agreement with that expected for a Langmuir-Hinshelwood mechanism requiring dissociative $\mathrm{H}_{2}$ chemisorption (see Figure S14b). ${ }^{63}$ Similar pressure dependences are reported at $>10$ bar $\mathrm{H}_{2}$ for D-glucose conversion over Raney nickel ${ }^{64}$ and $\mathrm{Ru}^{62,22}$ catalysts, although, in these instances, first-order kinetics were claimed, possibly indicative of reactor operation in a diffusion-limited regime. ${ }^{62}$ Increasing the hydrogen pressure from 5 bar to 20 bar induced a switchover in selectivity from predominantly $\mathrm{D}$-fructose to $\mathrm{D}$ -

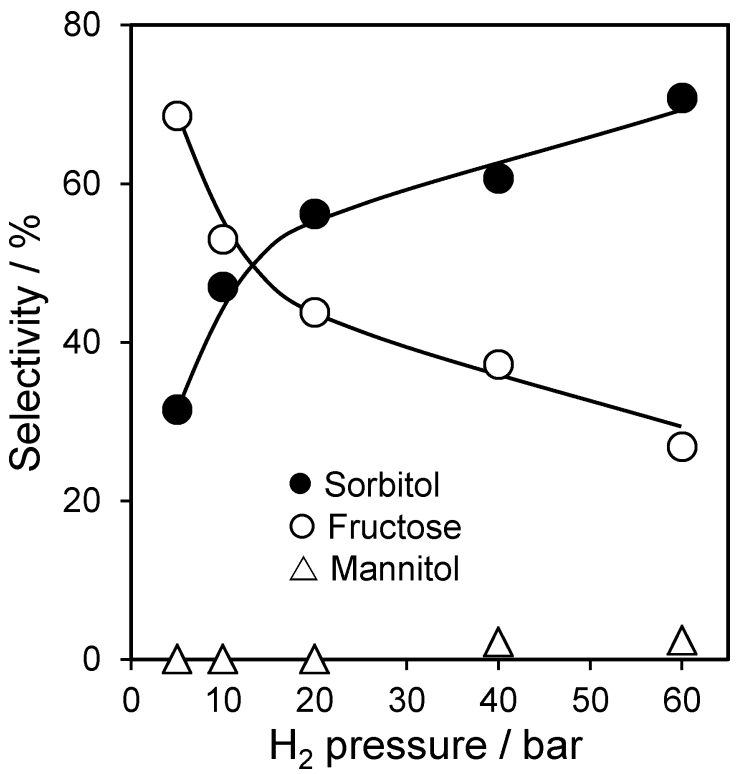

Figure 5. Influence of $\mathrm{H}_{2}$ pressure on relative product selectivity during the aqueous-phase hydrogenation of D-glucose over 1.5 wt \% Pt-SBA-15 catalyst at $140{ }^{\circ} \mathrm{C}$. Selectivities were calculated at $5 \%$ glucose conversion.

sorbitol, suggesting that the D-glucose isomerization pathway is inhibited over $\mathrm{H}_{2}$-saturated surfaces, which conversely (and unsurprisingly) favor the competing hydrogenation pathway. Carbon mass balances were independent of hydrogen pressure (Figure S14c), which we therefore infer exerted minimal influence on side reactions. Qualitatively similar behavior was observed for the lowest loading of Pt/SBA-15 catalyst (0.04 wt $\%$ ) (consisting of particle $3.8 \mathrm{~nm}$ in size), for which the order, with respect to $p_{\mathrm{H}_{2}}$, was 0.9 , and an increase in hydrogen pressure from 40 bar to 60 bar enhanced sorbitol selectivity from $12 \%$ to $15 \%$ (i.e., a similar factor to that observed in Figure 5).

In summary, electronically polarized $\mathrm{Pt}$ surfaces/interfaces favor the adsorption and activation of D-glucose molecules via $\mathrm{C}=\mathrm{O}$ of the aldose form, leading to the formation of an active and selective precursor to D-sorbitol. ${ }^{11,22}$ The selectivity to Dsorbitol is strongly dependent on the reaction temperature, which could also lead to the isomerization of D-glucose to Dfructose, which can subsequently lead to an increase in the selectivity/yield of D-mannitol. Therefore, based on the abovementioned results, it should be sensible to conclude that shorter reaction time, lower D-glucose concentration, lower reaction temperature, higher $\mathrm{H}_{2}$ pressure, and catalyst mass offer the best selectivity to D-sorbitol and a higher mass balance. ${ }^{17}$

\section{CONCLUSIONS}

Structure-activity relations in the aqueous phase hydrogenation of D-glucose to D-sorbitol were systematically investigated for $\mathrm{Pt}$ nanoparticles supported over either lowarea fumed silica or high-area mesoporous SBA-15 supports. Dsorbitol productivity via hydrogenation of the ring-opened aldose form of D-glucose was structure-insensitive for $\mathrm{Pt}$ particles between 3 and $17 \mathrm{~nm}$ in diameter, whereas competing D-glucose isomerization to D-fructose was favored by small, electron-deficient $\mathrm{Pt}$ particles; both reaction pathways proceeded independently of the choice of silica support. 
Moderate reaction temperatures $\left(<140{ }^{\circ} \mathrm{C}\right)$ and high hydrogen pressures suppress D-glucose isomerization to D-fructose (and its subsequent polymerization), maximizing D-sorbitol productivity. D-Mannitol does not epimerize to D-sorbitol under our reaction conditions. Our observation that large $\mathrm{Pt}$ nanoparticles and high $p_{\mathrm{H}_{2}}$ favor selective $\mathrm{C}=\mathrm{O}$ hydrogenation to the corresponding alcohols is in accordance with related studies on allylic and benzylic aldehydes, ${ }^{55}$ implying that particle size effects in Pt-catalyzed selective $\mathrm{C}=\mathrm{O}$ hydrogenations are a generic phenomenon.

\section{ASSOCIATED CONTENT}

\section{S Supporting Information}

The Supporting Information is available free of charge on the ACS Publications website at DOI: 10.1021/acscatal.6b02369.

Catalyst synthesis procedure and characterization data, along with full details of catalytic reaction data (PDF)

\section{AUTHOR INFORMATION}

\section{Corresponding Authors}

*E-mail: a.f.lee@aston.ac.uk (A. F. Lee).

*E-mail: k.wilson@aston.ac.uk (K. Wilson).

\section{Author Contributions}

The manuscript was written through contributions of all authors. All authors have given approval to the final version of the manuscript.

\section{Funding}

This research was supported by the EPSRC and UK Catalysis Hub (under Grant Nos. EP/K014749/1 and EP/K014706/1) and the British Council through the Global Innovation Initiative (under the GB3-Net project).

\section{Notes}

The authors declare no competing financial interest.

\section{REFERENCES}

(1) Lee, A. F.; Bennett, J. A.; Manayil, J. C.; Wilson, K. Chem. Soc. Rev. 2014, 43, 7887.

(2) Wilson, K.; Lee, A. F. In Advances in Biorefineries; Waldron, K., Ed.; Woodhead Publishing: Cambridge, U.K., 2014; p 624.

(3) van Putten, R.-J.; van der Waal, J. C.; de Jong, E.; Rasrendra, C. B.; Heeres, H. J.; de Vries, J. G. Chem. Rev. 2013, 113, 1499.

(4) Climent, M. J.; Corma, A.; Iborra, S. Green Chem. 2011, 13, 520.

(5) Tai, Z.; Lee, A. F.; Wilson, K. In Reaction Pathways and Mechanisms in Thermocatalytic Biomass Conversion I: Cellulose Structure, Depolymerization and Conversion by Heterogeneous Catalysts; Schlaf, M., Zhang, C. Z., Eds.; Springer: Singapore, 2016; p 123.

(6) Zhang, J.; Li, J.-B.; Wu, S.-B.; Liu, Y. Ind. Eng. Chem. Res. 2013, $52,11799$.

(7) Vilcocq, L.; Cabiac, A.; Especel, C.; Guillon, E.; Duprez, D. Oil Gas Sci. Technol. 2013, 68, 841.

(8) Wang, Y.; De, S.; Yan, N. Chem. Commun. 2016, 52, 6210.

(9) Brahme, P. H.; Doraiswamy, L. K. Ind. Eng. Chem. Process Des. Dev. 1976, 15, 130.

(10) Wisnlak, J.; Simon, R. Ind. Eng. Chem. Prod. Res. Dev. 1979, 18, 50.

(11) Gallezot, P.; Cerino, P. J.; Blanc, B.; Flèche, G.; Fuertes, P. J. Catal. 1994, 146, 93.

(12) Kusserow, B.; Schimpf, S.; Claus, P. Adv. Synth. Catal. 2003, $345,289$.

(13) Liu, J.; Bai, P.; Zhao, X. S. Phys. Chem. Chem. Phys. 2011, 13, 3758 .

(14) Mishra, D. K.; Dabbawala, A. A.; Park, J. J.; Jhung, S. H.; Hwang, J.-S. Catal. Today 2014, 232, 99.
(15) Zhang, J.; Lin, L.; Zhang, J.; Shi, J. Carbohydr. Res. 2011, 346, 1327.

(16) Sapunov, V. N.; Grigoryev, M. Y.; Sulman, E. M.; Konyaeva, M. B.; Matveeva, V. G. J. Phys. Chem. A 2013, 117, 4073.

(17) Gallezot, P.; Nicolaus, N.; Flèche, G.; Fuertes, P.; Perrard, A. J. Catal. 1998, 180, 51.

(18) Perrard, A.; Gallezot, P.; Joly, J.-P.; Durand, R.; Baljou, C.; Coq, B.; Trens, P. Appl. Catal., A 2007, 331, 100.

(19) Déchamp, N.; Gamez, A.; Perrard, A.; Gallezot, P. Catal. Today 1995, 24, 29.

(20) Weiss, J. Trans. Faraday Soc. 1941, 37, 782.

(21) Arena, B. J. Appl. Catal., A 1992, 87, 219.

(22) Guo, H.; Li, H.; Zhu, J.; Ye, W.; Qiao, M.; Dai, W. J. Mol. Catal. A: Chem. 2003, 200, 213.

(23) Li, H.; Wang, W.; Fa Deng, J. J. Catal. 2000, 191, 257.

(24) Li, H.; Deng, J.-F. J. Chem. Technol. Biotechnol. 2001, 76, 985.

(25) Bratlie, K. M.; Lee, H.; Komvopoulos, K.; Yang, P.; Somorjai, G. A. Nano Lett. 2007, 7, 3097.

(26) Lordi, V.; Yao, N.; Wei, J. Chem. Mater. 2001, 13, 733.

(27) Zhang, X.; Liu, P.; Wu, Y.; Yao, Y.; Wang, J. Catal. Lett. 2010, 137, 210.

(28) Giang, C.; Osatiashtiani, A.; dos Santos, V.; Lee, A.; Wilson, D.; Waldron, K.; Wilson, K. Catalysts 2014, 4, 414.

(29) Tathod, A.; Kane, T.; Sanil, E. S.; Dhepe, P. L. J. Mol. Catal. A: Chem. 2014, 388-389, 90.

(30) Lazaridis, P. A.; Karakoulia, S.; Delimitis, A.; Coman, S. M.; Parvulescu, V. I.; Triantafyllidis, K. S. Catal. Today 2015, 257, 281.

(31) Liu, C. W.; Zhang, C. H.; Liu, K. K.; Wang, Y.; Fan, G. X.; Sun, S. K.; Xu, J.; Zhu, Y. L.; Li, Y. W. Biomass Bioenergy 2015, 72, 189.

(32) Heinen, A. W.; Peters, J. A.; van Bekkum, H. Carbohydr. Res. 2000, 328, 449 .

(33) West, R. M.; Tucker, M. H.; Braden, D. J.; Dumesic, J. A. Catal. Commun. 2009, 10, 1743.

(34) Kon, K.; Onodera, W.; Shimizu, K. Catal. Sci. Technol. 2014, 4, 3227.

(35) Cai, H. L.; Li, C. Z.; Wang, A. Q.; Zhang, T. Catal. Today 2014, 234, 59.

(36) Fukuoka, A.; Dhepe, P. L. Angew. Chem., Int. Ed. 2006, 45, 5161.

(37) Kobayashi, H.; Ito, Y.; Komanoya, T.; Hosaka, Y.; Dhepe, P. L.; Kasai, K.; Hara, K.; Fukuoka, A. Green Chem. 2011, 13, 326.

(38) Wilson, K.; Lee, A. F. Philos. Trans. R. Soc., A 2016, 374, 20150081.

(39) Durndell, L. J.; Parlett, C. M. A.; Hondow, N. S.; Wilson, K.; Lee, A. F. Nanoscale 2013, 5, 5412.

(40) Chen, R.; Chen, Z.; Ma, B.; Hao, X.; Kapur, N.; Hyun, J.; Cho, K.; Shan, B. Comput. Theor. Chem. 2012, 987, 77.

(41) Longwitz, S. R.; Schnadt, J.; Vestergaard, E. K.; Vang, R. T.; Stensgaard, I.; Brune, H.; Besenbacher, F. J. Phys. Chem. B 2004, 108, 14497.

(42) Maris, E. P.; Ketchie, W. C.; Oleshko, V.; Davis, R. J. J. Phys. Chem. B 2006, 110, 7869.

(43) De Bruijn, J. M.; Kieboom, A. P. G.; Bekkiun, H. V. J. Carbohydr. Chem. 1986, 5, 561.

(44) Patil, S. K. R.; Lund, C. R. F. Energy Fuels 2011, 25, 4745.

(45) Guo, X.; Wang, X.; Guan, J.; Chen, X.; Qin, Z.; Mu, X.; Xian, M. Chin. J. Catal. 2014, 35, 733.

(46) Mishra, D. K.; Lee, J.-M.; Chang, J.-S.; Hwang, J.-S. Catal. Today 2012, 185, 104.

(47) Ahmed, M. J. Heat Mass Transfer 2012, 48, 343.

(48) Kanie, Y.; Akiyama, K.; Iwamoto, M. Catal. Today 2011, 178, 58

(49) Qian, X. J. Phys. Chem. B 2013, 117, 11460

(50) Plazinski, W.; Plazinska, A.; Drach, M. Phys. Chem. Chem. Phys. 2015, 17, 21622.

(51) Trinh, Q. T.; Chethana, B. K.; Mushrif, S. H. J. Phys. Chem. C 2015, 119, 17137.

(52) Zhao, H.; Kim, J.; Koel, B. E. Surf. Sci. 2003, 538, 147.

(53) Grass, M. E.; Rioux, R. M.; Somorjai, G. A. Catal. Lett. 2009, $128,1$. 
(54) Prashar, A. K.; Mayadevi, S.; Nandini Devi, R. Catal. Commun. 2012, 28, 42.

(55) Durndell, L. J.; Parlett, C. M. A.; Hondow, N. S.; Isaacs, M. A.; Wilson, K.; Lee, A. F. Sci. Rep. 2015, 5, 9425.

(56) Chatterjee, C.; Pong, F.; Sen, A. Green Chem. 2015, 17, 40.

(57) Yang, G.; Pidko, E. A.; Hensen, E. J. M. ChemSusChem 2013, 6, 1688.

(58) Ganji, M. D.; Emami Skardi, F. S. Fullerenes, Nanotubes, Carbon Nanostruct. 2015, 23, 273.

(59) Alcalá, R.; Greeley, J.; Mavrikakis, M.; Dumesic, J. A. J. Chem. Phys. 2002, 116, 8973.

(60) Schimpf, S.; Louis, C.; Claus, P. Appl. Catal., A 2007, 318, 45.

(61) Delidovich, I.; Palkovits, R. Catal. Sci. Technol. 2014, 4, 4322.

(62) Crezee, E.; Hoffer, B. W.; Berger, R. J.; Makkee, M.; Kapteijn, F.; Moulijn, J. A. Appl. Catal., A 2003, 251, 1.

(63) Olivas, A.; Jerdev, D. I.; Koel, B. E. J. Catal. 2004, 222, 285.

(64) Hoffer, B. W.; Crezee, E.; Mooijman, P. R. M.; van Langeveld, A. D.; Kapteijn, F.; Moulijn, J. A. Catal. Today 2003, 79-80, 35. 